\title{
BMJ Open Health conditions in a cohort of New Zealand Vietnam veterans: hospital admissions between 1988 and 2009
}

\author{
Brian Cox, ${ }^{1}$ David McBride, ${ }^{2}$ John Broughton, ${ }^{3}$ Darryl Tong ${ }^{4}$
}

To cite: Cox B, McBride D, Broughton J, et al. Health conditions in a cohort of New Zealand Vietnam veterans: hospital admissions between 1988 and 2009. BMJ Open 2015;5:e008409. doi:10.1136/bmjopen-2015008409

- Prepublication history and additional material is available. To view please visit the journal (http://dx.doi.org/ 10.1136/bmjopen-2015008409).

Received 8 May 2015 Revised 12 October 2015 Accepted 14 October 2015

CrossMark

\begin{abstract}
${ }^{1}$ Hugh Adam Cancer Epidemiology Unit, University of Otago, Dunedin,

New Zealand

${ }^{2}$ Department of Preventive and Social Medicine, University of Otago, Dunedin, New Zealand

${ }^{3}$ Ngai Tahu Māori Health Research Unit, University of Otago, Dunedin, New Zealand ${ }^{4}$ Department of Oral Diagnostic and Surgical Sciences, University of Otago, Dunedin, New Zealand
\end{abstract}

Correspondence to Dr David McBride; david.mcbride@otago.ac.nz

\section{ABSTRACT}

Objectives: To inform the provision of support to veterans by analysing hospital discharge data, thereby identifying which conditions show an excess risk, require specific management strategies and deserve further investigation.

Setting: Tertiary level care, including all public and private New Zealand hospitals.

Participants: All New Zealand Vietnam veterans with service between 1964 and 1972.

Primary outcome measures: Standardised hospitalisation ratios (SHRs) were calculated based on the number of first observed hospital admissions for a condition, those expected being based on New Zealand national hospitalisation rates.

Results: The SHR for all causes of hospitalisation was $1.18,95 \% \mathrm{Cl} 1.15$ to 1.21 , with modest increases for the major common causes, cardio and cerebrovascular disease. Admission rates for chronic renal failure and chronic obstructive pulmonary disease were highest in the 2006-2009 time period. The highest statistically significant hospitalisation risk was for alcohol-related mental disorder, SHR 1.91, 99\% Cl 1.39 to 2.43 .

Conclusions: Chronic renal failure has limited attribution to veteran service but along with chronic obstructive pulmonary disease has the potential to have high costs both to the individual and the health system. We suggest that routine surveillance of veterans by way of a 'flag' in national and primary care databases would facilitate the recognition of servicerelated conditions and the appropriate provision of healthcare.

\section{INTRODUCTION}

Veterans of war and conflict are a population at risk from illnesses and injuries sustained during war or 'war-like' service and for which they are entitled to support from veteran's health organisations. These organisations may include community level self-help groups, patient advocacy services, veteranfocused rest home and hospital facilities, all of which can assist veterans in seeking the appropriate advice and referrals for further evaluation. At a government level, support

\section{Strengths and limitations of this study}

- This is the first complete census of a Vietnam veteran cohort using routinely collected data and facilitating a comparison with general population rates.

- The 'healthy soldier' effect often confounds the interpretation of military cohort studies, but the effect decreases with time, seen here for many causes of morbidity.

- The national comparisons reveal ongoing problems with drugs and alcohol, with smoking a likely cause of respiratory disease and contributory factor to renal failure: this indicates a priority for screening and preventive measures in this group.

- Limitations were a follow-up of $84 \%$ and an absence of information on smoking and ethnicity. Ethnicity should not be having a strong effect, but if the smoking prevalence was different in other veteran groups it might limit the generalisability of our results.

- The psychiatric admissions to hospital are unlikely to reflect the true size of the problem.

takes the form of ministerial departments and services such as New Zealand Veterans Affairs (NZVA). NZVA provides a range of services including pensions, lump sum payments and assistance with paying medically related costs such as travel. Medical treatment costs may be covered, but this is discretionary, limited to 'service-related conditions' and only available when there is no other source of public or other funding.

Service-related conditions are those injuries, illnesses or conditions presumed due to specific military deployments where the clinical or epidemiological evidence supports an association. The New Zealand list of 'presumed conditions' relate to former prisoners of war, those exposed to nuclear radiation, Vietnam and Gulf War veterans.

Vietnam veterans form a significant proportion of those in need of such support from NZVA, the presumption here residing 
in the 'sentinel' exposure to Agent Orange herbicide during their Vietnam deployment. The evidence for the list came from the US Department of Veterans Affairs and the Institute of Medicine of the US National Academy of Sciences (IOM), based on cumulative reviews of mechanistic data and epidemiological studies. ${ }^{1}$ The results of the mortality and cancer incidence cohort study of our New Zealand Vietnam veterans were largely consistent with the list of presumed conditions. ${ }^{2}$ For conditions other than cancer, decisions on support are made clinically and administratively by NZVA on a 'case by case' basis. A recent change in New Zealand veteran legislation, the Veteran Support Act 2014, has brought more objectivity to the decisionmaking process by adopting the Australian 'Statements of Principle', an evidence base for causation developed by the Australian Repatriation Medical Authority. The Statements of Principle assist the Australian Department of Veterans Affairs to make informed decisions about the provision of healthcare and benefits. ${ }^{3}$ The Statements of Principle are based on 'sound medicalscientific evidence' with two standards of proof, 'reasonable hypothesis', the evidence being indicative of an association, or on 'balance of probability', the totality of the evidence reflecting an association which is more probable than not. The lesser, indicative, standard of proof reflects a spirit of benevolence towards veterans whose service has put them 'at harms way'. Providing that the patient identifies their veteran status to a health practitioner, those health conditions most likely to be recognised in the community practice setting are those associated with psychological and physical trauma. When considering other causes of morbidity, mechanistic data may help with hypothesis generation and general population studies build the evidence base. This knowledge contributes to the development of the Statements of Principle and also assists the clinical reasoning process. The potential for quality data lies however in militaryspecific studies examining the relationship between war-like deployment, specific exposures and health outcomes. These studies have the disadvantages of expense, being also complex and difficult to interpret. For example, Gulf War syndrome has highly variable symptomology (such as fatigue, rash, musculoskeletal pain and memory loss) and has been identified in both deployed and non-deployed personnel, thus illustrating the difficulty in identifying an attributable cause, especially in terms of toxic exposure. ${ }^{4}$

We therefore advocate the routine surveillance of military populations to identify those conditions with service associations, thus informing both the recognition of veteran illness and the decision-making processes. Routinely collected data, although cost-effective, does have drawbacks, requiring the consideration of selection effects. The cohort of Vietnam veterans, like other veteran cohorts, was subject to a recruitment process resulting in the 'healthy soldier effect', with veterans, at least initially, showing better health than their general population counterparts. A mortality and cancer incidence study of this cohort ${ }^{2}$ showed mortality that was significantly better than the general population but revealing an increased risk for some forms of cancer.

The aim of this study was to inform the provision of support to veterans by carrying out a record linkage study, thereby identifying which conditions show an excess risk, require specific management strategies and deserve further investigation.

\section{Methods}

The methods have been described previously. ${ }^{2}$ The cohort consisted of the 3394 men and women on the database of NZVA who served in Vietnam between 1962 and 1971. With 36 recorded as killed in action (we identified one more) or died of wounds or accidents, we searched for the remaining 3358, tracing these individuals using National Health Index (NHI) numbers, which are unique to each person, also carrying out additional searches of the electoral roll. Unfortunately, we had to exclude the 23 women, who formed too small a group for separate analysis. Of the remainder, we managed to trace 2783 individuals, or $83.8 \%$, of those who served.

Follow-up started on 1 January 1988, the date from which electronic NHI linkage was available, with follow-up to 31 December 2009. The hospital events records contained codes for the principal diagnosis, medical procedure or external cause that prompted a hospital admission during the period, coded by the nosologists within each District Health Board using the International Statistical Classification of Diseases and Related Health Problems, Australian Modification (ICD-10 CMA) standard and its antecedents.

To account for multiple admissions for the same condition, particularly the case for chronic illness and influenced by comorbidity, we restricted the analysis to the first hospital admission for each cause. Data on lifestyle factors and the ethnicity of members of the cohort were not available.

The person-years of follow-up for the cohort through each 5-year age category from 30 or more years of age were calculated for each of the five time periods, 1988 1990, 1991-1995, 1996-2000, 2001-2005 and 2006-2009.

The corresponding national male age-specific hospitalisation rates for these time periods were calculated from annual numbers of hospitalisations published by the Ministry of Health and the mean annual usually resident population estimates published by Statistics New Zealand. The rates were then applied to the personyears of follow-up of the cohort of veterans for the appropriate time periods and age groups to calculate the numbers of hospitalisations expected in the cohort.

Using these data, the numbers of hospitalisations observed in veterans were divided by the numbers expected from the hospitalisation rate of the general population of the same age group during the same time periods to produce a standardised hospitalisation ratio 
(SHR). A conservative approach was taken to assessing multiple comparisons by calculating $99 \%$ rather than 95\% CIs using the Poisson distribution.

\section{RESULTS}

The SHRs for the categories of admission most frequently experienced by veterans are shown in table 1 . For cancers the standardised incidence rates presented in our previous report ${ }^{2}$ provide a better estimate of the risks of cancer and are not shown here.

The SHR for all causes of hospitalisation was 1.18, 99\% CI 1.15 to 1.21 , indicating an $18 \%$ increase in hospitalisations for this veteran group.

Modest increases were found for the common major causes in this group, cardio and cerebrovascular diseases. The SHR for chronic renal failure (CRF) showed a small but significant elevation, with emphysema and chronic bronchitis contributing to chronic obstructive pulmonary disease (COPD) and a smaller increase for pneumonia. Pneumonia, phlebitis and gastroduodenal ulcer had SHRs in excess of 1.5. Musculoskeletal conditions with excess risks were rheumatoid arthritis, osteoarthrosis, 'other' joint disorders and joint injuries.

The highest statistically significant risk was found for alcohol-related mental disorders, with a SHR of 1.91, 99\% CI 1.39 to 2.43; hospitalisation for substance-related mental disorders was also increased but occurred infrequently and did not reach the level of statistical significance chosen. Alcoholic liver disease was not significantly increased; however, 'other' liver diseases were, as were 'other' mental disorders. In contrast, schizophrenia displayed a significantly reduced risk of hospitalisation.

The analysis by time period is shown in table 2 for major causes. Online supplementary table S1 supplies data on the full range of diagnoses included in table 1 .

All reasons for hospitalisation were slightly but significantly reduced in the earliest time period, with, however, an increasing trend over time. Hospitalisations showing a twofold or more increased risk in the most recent quinquennium were diabetes, retinal disease, phlebitis, pneumonia, COPD, intestinal obstruction, other liver disease, CRF, skin infection and joint injury.

\section{DISCUSSION}

The overall results showed a small but significant increase in hospital admissions for Vietnam veterans. We observed modest increases for the common conditions expected in a cohort of this age, those related to ischaemic heart and cerebrovascular disease. There was a more marked increase in risk of hospitalisation for COPD for a clinically significant number of individuals and a similar increase for numerically smaller groups, those with alcohol-related mental disorder, gastroduodenal ulcer, liver disorders, rheumatoid arthritis and 'other' joint disorders. Stratification by time period showed acceleration in hospitalisation risk during later time periods, most marked in 'all causes', COPD and CRF. The combination of increased hospitalisation for cardio and cerebrovascular disease, as well as CRF and retinal disease in recent time periods, suggests that hypertension may have been more common in Vietnam veterans. For those conditions strongly suspected as being due to war service, psychological disorders, there was little evidence of increased hospitalisation. In contrast, there were a small but significant number of veterans with alcohol problems, and even though clinically non-significant, a higher hospitalisation rate for substance abuse.

The strengths of the study lay in a complete census of the population, not a sample, giving adequate statistical power to assess hospitalisation for many common diagnoses. The disease coding is carried out by trained coders and has good validity, the exception being for psychiatric disorders where there may be problems with both clinical diagnoses and subsequent coding. ${ }^{5}$

The limitations include a follow-up of $84 \%$, which raises the possibility of bias if those lost to follow-up had a different risk of hospitalisation. Ten per cent of those lost to follow-up lived overseas, the majority in Australia. If veterans who migrated to Australia were less likely to be hospitalised, our results may have overestimated the hospitalisation rate of veterans and vice versa. We do not think that this is so, because Vietnam veterans resident in Australia are still eligible for NZVA benefits; however, the most conservative assumption in a sensitivity analysis is to assume that those lost to follow-up were not hospitalised. This reduced the 'all causes' SHR to 1.02 , 99\% CI 0.99 to 1.04 , with the lower bound of the CIs below unity for several conditions (see online supplementary table S2). We do not have data for Australian Vietnam veteran hospitalisation, but standardised incidence ratios for cancers in our cohort ${ }^{2}$ tended to be lower than that of Australian Army Vietnam veterans, which suggests that our findings may in fact be an underestimate.

The cohort is of such an age that chronic illness becomes more frequent, with multiple hospital admission for the same condition along with an increased likelihood of comorbidity. We report here the principal discharge code, the validity of has been which is likely to be correct for major causes of admission such as acute myocardial infarction. ${ }^{6}$ Comorbidities are associated with adverse outcomes, for example, osteoarthritis appears to increase the risk of hospitalisation for cardiovascular disease, but the relationships are complex. ${ }^{7}$

In addition, the recording of private hospital admissions was incomplete prior to 1994, subsequently improved, but could only be considered complete from about 2001 onwards. Differential admission of veterans to private hospitals, especially during the earlier periods, could have resulted in underestimation or overestimation of the risk of hospital admissions for some conditions in the cohort. However, inspection of the complete results of the stratified analysis (see online supplementary table S1) did not show strong evidence of any systematic difference. Lastly, we did not have information on many confounders, particularly smoking and ethnicity. The 
Table 1 Standardised hospitalisation rates (SHRs) 1988-2009

\begin{tabular}{|c|c|c|c|c|}
\hline Condition & Total observed & Total expected & SHR & $99 \% \mathrm{Cl}$ \\
\hline All causes of hospitalisation & 10348 & 8775.5 & 1.18 & 1.15 to 1.21 \\
\hline \multicolumn{5}{|l|}{ Endocrine disorders } \\
\hline Thyroid disease & 7 & 5.0 & 1.41 & 0.04 to 2.78 \\
\hline Diabetes & 151 & 132.3 & 1.14 & 0.90 to 1.38 \\
\hline Gout and other crystal diseases & 40 & 26.6 & 1.50 & 0.89 to 2.12 \\
\hline \multicolumn{5}{|l|}{ Cardiovascular } \\
\hline Acute myocardial infarction & 331 & 285.2 & 1.16 & 1.00 to 1.33 \\
\hline Coronary atherosclerosis & 659 & 520.4 & 1.27 & 1.14 to 1.39 \\
\hline Chest pain & 350 & 259.7 & 1.35 & 1.16 to 1.53 \\
\hline Cardiac arrest & 9 & 5.8 & 1.54 & 0.22 to 2.86 \\
\hline Dysrhythmia & 261 & 205.0 & 1.27 & 1.07 to 1.48 \\
\hline Congestive heart failure & 121 & 118.8 & 1.02 & 0.78 to 1.26 \\
\hline Acute cerebrovascular disease & 170 & 130.2 & 1.31 & 1.05 to 1.56 \\
\hline Peripheral atherosclerosis & 70 & 59.7 & 1.17 & 0.81 to 1.53 \\
\hline Aneurysm & 45 & 30.5 & 1.47 & 0.91 to 2.04 \\
\hline Phlebitis & 51 & 30.5 & 1.67 & 1.07 to 2.28 \\
\hline Syncope & 100 & 67.5 & 1.47 & 1.18 to 1.76 \\
\hline \multicolumn{5}{|l|}{ Respiratory } \\
\hline Chronic obstructive pulmonary disease & 300 & 178.3 & 1.68 & 1.43 to 1.93 \\
\hline Pneumonia & 174 & 127.9 & 1.36 & 1.09 to 1.63 \\
\hline Asthma & 33 & 39.4 & 0.84 & 0.46 to 1.21 \\
\hline \multicolumn{5}{|l|}{ Gastrointestinal and hepatobiliary } \\
\hline Oesophageal disorders & 102 & 88.3 & 1.16 & 0.86 to 1.45 \\
\hline Gastroduodenal ulcer & 44 & 24.5 & 1.80 & 1.10 to 2.50 \\
\hline Gastritis & 48 & 64.3 & 0.75 & 0.47 to 1.02 \\
\hline Appendicitis & 35 & 31.4 & 1.12 & 0.63 to 1.60 \\
\hline Abdominal hernia & 156 & 169.6 & 0.92 & 0.73 to 1.11 \\
\hline Intestinal obstruction & 65 & 44.7 & 1.45 & 0.99 to 1.92 \\
\hline Diverticulosis & 50 & 44.4 & 1.13 & 0.72 to 1.54 \\
\hline Anal/rectal disorders & 79 & 60.3 & 1.31 & 0.93 to 1.69 \\
\hline Biliary disorders & 132 & 104.0 & 1.27 & 0.98 to 1.55 \\
\hline Alcoholic liver disease & 11 & 10.3 & 1.07 & 0.24 to 1.90 \\
\hline Other liver disease & 48 & 25.8 & 1.86 & 1.17 to 2.55 \\
\hline Pancreatic disease & 24 & 29.8 & 0.81 & 0.38 to 1.23 \\
\hline Abdominal pain & 133 & 112.5 & 1.19 & 0.99 to 1.39 \\
\hline Gastrointestinal haemorrhage & 106 & 80.6 & 1.31 & 0.99 to 1.64 \\
\hline \multicolumn{5}{|l|}{ Mental and neurological } \\
\hline Affective disorder & 58 & 60.5 & 0.96 & 0.63 to 1.28 \\
\hline Anxiety disorder & 22 & 14.2 & 1.55 & 0.70 to 2.40 \\
\hline Schizophrenia or related disorders & 21 & 43.0 & 0.49 & 0.21 to 0.76 \\
\hline Alcohol-related mental disorders & 89 & 46.6 & 1.91 & 1.39 to 2.43 \\
\hline Substance-abuse-related mental disorders & 8 & 3.4 & 2.39 & 0.21 to 4.56 \\
\hline Headache or migraine & 34 & 23.8 & 1.43 & 0.80 to 2.06 \\
\hline Senility or organic mental illness & 28 & 29.4 & 0.95 & 0.49 to 1.41 \\
\hline Epilepsy or convulsions & 25 & 28.3 & 0.88 & 0.43 to 1.34 \\
\hline Other nervous disorders & 135 & 102.5 & 1.32 & 1.02 to 1.61 \\
\hline \multicolumn{5}{|l|}{ Eye and ear } \\
\hline Retinal disease & 31 & 22.9 & 1.35 & 0.73 to 1.98 \\
\hline Cataract & 99 & 89.2 & 1.11 & 0.82 to 1.40 \\
\hline Ear disease other than dizziness & 44 & 58.3 & 0.75 & 0.46 to 1.05 \\
\hline \multicolumn{5}{|l|}{ Bone and joint } \\
\hline Infective arthritis & 26 & 18.7 & 1.39 & 0.85 to 1.92 \\
\hline Rheumatoid arthritis & 25 & 14.7 & 1.70 & 1.03 to 2.36 \\
\hline Osteoarthrosis & 179 & 135.8 & 1.32 & 1.12 to 1.51 \\
\hline Other joint diseases & 77 & 57.3 & 1.34 & 1.04 to 1.64 \\
\hline Back problem & 130 & 121.5 & 1.07 & 0.88 to 1.25 \\
\hline Systemic lupus erythematosis & 5 & 2.8 & 1.82 & 0.22 to 3.41 \\
\hline Other connective tissue disease & 169 & 136.5 & 1.25 & 1.06 to 1.44 \\
\hline
\end{tabular}




\begin{tabular}{|c|c|c|c|c|}
\hline Condition & Total observed & Total expected & SHR & $99 \% \mathrm{Cl}$ \\
\hline \multicolumn{5}{|l|}{ Genitourinary } \\
\hline Chronic renal failure & 461 & 380.8 & 1.21 & 1.07 to 1.36 \\
\hline Urinary tract infection & 47 & 44.4 & 1.06 & 0.66 to 1.46 \\
\hline Urinary stones & 117 & 110.3 & 1.06 & 0.81 to 1.31 \\
\hline Benign prostatic hypertrophy & 81 & 73.2 & 1.11 & 0.79 to 1.42 \\
\hline \multicolumn{5}{|l|}{ Skin } \\
\hline Skin infection & 140 & 114.9 & 1.22 & 1.15 to 1.21 \\
\hline Other skin diseases & 60 & 51.4 & 1.17 & 0.87 to 1.46 \\
\hline \multicolumn{5}{|l|}{ Injuries } \\
\hline Joint injury & 97 & 69.8 & 1.40 & 1.12 to 1.67 \\
\hline Fracture of hip & 27 & 21.1 & 1.29 & 0.81 to 1.77 \\
\hline Fracture of arm & 65 & 66.7 & 0.97 & 0.74 to 1.21 \\
\hline Fracture of leg & 66 & 71.2 & 0.95 & 0.73 to 1.17 \\
\hline Fracture of skull or face & 18 & 23.1 & 0.80 & 0.44 to 1.16 \\
\hline Other fracture & 86 & 64.6 & 1.33 & 1.05 to 1.61 \\
\hline Sprain & 53 & 40.7 & 1.32 & 0.97 to 1.67 \\
\hline Intracranial injury & 49 & 46.5 & 1.06 & 0.76 to 1.35 \\
\hline Crush injury & 16 & 22.2 & 0.76 & 0.40 to 1.11 \\
\hline Open wound head & 27 & 26.8 & 1.00 & 0.62 to 1.37 \\
\hline Open wound other than head & 99 & 85.1 & 1.15 & 0.92 to 1.38 \\
\hline \multicolumn{5}{|l|}{ Other } \\
\hline Rehabilitation & 144 & 131.6 & 1.10 & 0.92 to 1.28 \\
\hline Other aftercare & 181 & 125.2 & 1.44 & 1.23 to 1.65 \\
\hline Unclassified & 85 & 115.2 & 1.23 & 1.03 to 1.44 \\
\hline Complication of a device & 128 & 119.4 & 1.07 & 0.88 to 1.25 \\
\hline Complication of a procedure & 155 & 126.5 & 1.22 & 1.03 to 1.41 \\
\hline Benign neoplasms & 111 & 83.0 & 1.34 & 1.01 to 1.66 \\
\hline
\end{tabular}

mortality study did show evidence of an increased risk of oral and lung cancers, both smoking related, but no other systematic smoking-related influence. As regards ethnicity, Māori are known to have poorer health overall and for many conditions, but there was little evidence of such confounding in the mortality analysis. ${ }^{2}$

Interpretation of the results requires consideration of the healthy soldier bias. The application and selection process for military service, and further selection prior to operational deployment, results in a cohort with initially lower disease incidence and mortality than the general population. A comparison military population may enable considerable control of the healthy soldier effect, but this too may need to be carefully selected. However, the healthy soldier effect does, for most conditions, diminish with duration of follow-up. ${ }^{8}{ }^{9}$ The low initial SHRs can be followed by a gradual increase when the incidence of morbidity and mortality of the cohort attains, or can exceed, that of the general population. The effect is most marked for conditions that can be detected at recruitment, seen here, for example, with schizophrenia. The effect has been shown to differ between subgroups within defence forces, varies markedly between different causes of death, and changes with time. ${ }^{9}$ It is a phenomenon which, as here, complicates the interpretation of military cohort studies. For example, the increase in SHRs for COPD may be due to a 'catching up' phase from a greater past prevalence of smoking, may be due to an environmental exposure associated with service, or may simply reflect the healthy soldier effect. The Statements of Principle identify COPD as a service-related disorder, associated with, for example, the inhalation of respiratory irritants, but CRF has not been adopted.

Although Australian Vietnam veterans hospitalisation data are not available, their mortality and cancer incidence $^{1011}$ is comparable with that in our previous study. ${ }^{2}$ Some morbidity data are available in that a random sample of 1000 Australian veterans was selected from a database of 57643 individuals posted to Vietnam and surveyed twice, initially between 1990 and 1993, then again between 2003 and 2006. ${ }^{12}$ Personal interviews, based on the instruments used by the Australian Bureau of Statistics National Health Survey, assessed physical and psychiatric health. The number of cases expected for each condition was obtained, matched for age and sex, from the national survey being carried out at approximately similar times. The conditions with the highest relative prevalence (RP) on the second survey were respiratory conditions, with an RP for chronic bronchitis of $2.9,95 \%$ CI 2.18 to 3.63 ; angina with an RP of 2.34, $95 \%$ CI 1.68 to 2.99; tinnitus RP 5.96, 95\% CI 5.36 to 6.57; and haemorrhoids, RP 7.65, 95\% CI 6.13 to 9.17. Only 3 of 20 psychiatric diagnoses for which comparative data were available failed to show elevations: alcohol and drug problems had a prevalence of $15.7 \%$, RP $8.75,95 \%$ 
Table 2 Standardised rates of first hospitalisation for major causes by time period

\begin{tabular}{|c|c|c|c|c|}
\hline Condition & Observed & Expected & SHR & $99 \% \mathrm{Cl}$ \\
\hline \multicolumn{5}{|l|}{ All causes } \\
\hline $1988-1990$ & 581 & 675.5 & 0.86 & 0.77 to 0.96 \\
\hline 1991-1995 & 1356 & 1458.3 & 0.93 & 0.87 to 1.00 \\
\hline 1996-2000 & 2093 & 2034.9 & 1.03 & 0.97 to 1.09 \\
\hline 2001-2005 & 3144 & 2803.4 & 1.12 & 1.07 to 1.17 \\
\hline 2006-2009 & 3186 & 1811.2 & 1.76 & 1.68 to 1.84 \\
\hline 1988-2009 & 10348 & 8775.5 & 1.18 & 1.15 to 1.21 \\
\hline \multicolumn{5}{|c|}{ Acute myocardial infarction } \\
\hline $1988-1990$ & 27 & 20.4 & 1.33 & 0.76 to 2.14 \\
\hline 1991-1995 & 48 & 46.0 & 1.04 & 0.70 to 1.50 \\
\hline 1996-2000 & 69 & 60.8 & 1.14 & 0.81 to 1.54 \\
\hline 2001-2005 & 109 & 99.4 & 1.10 & 0.84 to 1.40 \\
\hline 2006-2009 & 81 & 59.4 & 1.36 & 1.00 to 1.81 \\
\hline 1988-2009 & 331 & 285.2 & 1.16 & 1.00 to 1.34 \\
\hline \multicolumn{5}{|c|}{ Coronary atherosclerosis } \\
\hline $1988-1990$ & 47 & 42.3 & 1.11 & 0.74 to 1.60 \\
\hline 1991-1995 & 138 & 106.6 & 1.29 & 1.03 to 1.61 \\
\hline 1996-2000 & 190 & 159.6 & 1.19 & 0.98 to 1.43 \\
\hline 2001-2005 & 179 & 146.1 & 1.23 & 1.00 to 1.48 \\
\hline 2006-2009 & 108 & 66.7 & 1.62 & 1.25 to 2.07 \\
\hline 1988-2009 & 659 & 520.4 & 1.27 & 1.14 to 1.40 \\
\hline \multicolumn{5}{|l|}{ Chest pain } \\
\hline $1988-1990$ & 17 & 17.8 & 0.96 & 0.46 to 1.73 \\
\hline 1991-1995 & 43 & 40.6 & 1.06 & 0.69 to 1.55 \\
\hline 1996-2000 & 71 & 55.1 & 1.29 & 0.93 to 1.74 \\
\hline 2001-2005 & 106 & 86.6 & 1.22 & 0.94 to 1.57 \\
\hline 2006-2009 & 113 & 59.7 & 1.89 & 1.47 to 2.40 \\
\hline 1988-2009 & 350 & 259.8 & 1.35 & 1.17 to 1.54 \\
\hline \multicolumn{5}{|c|}{ Chronic obstructive pulmonary disease } \\
\hline $1988-1990$ & 5 & 7.5 & 0.67 & 0.14 to 1.89 \\
\hline $1991-1995$ & 28 & 20.6 & 1.36 & 0.79 to 2.17 \\
\hline 1996-2000 & 60 & 38.2 & 1.57 & 1.10 to 2.17 \\
\hline 2001-2005 & 107 & 65.2 & 1.64 & 1.26 to 2.10 \\
\hline 2006-2009 & 100 & 46.9 & 2.13 & 1.62 to 2.75 \\
\hline 1988-2009 & 300 & 178.3 & 1.68 & 1.44 to 1.95 \\
\hline \multicolumn{5}{|c|}{ Chronic renal failure } \\
\hline $1988-1990$ & 1 & 2.6 & 0.38 & 0.00 to 2.82 \\
\hline $1991-1995$ & 29 & 20.7 & 1.40 & 0.82 to 2.23 \\
\hline 1996-2000 & 8 & 66.2 & 0.12 & 0.04 to 0.28 \\
\hline 2001-2005 & 153 & 189.1 & 0.81 & 0.65 to 0.99 \\
\hline 2006-2009 & 270 & 102.2 & 2.64 & 2.25 to 3.09 \\
\hline 1988-2009 & 461 & 380.8 & 1.21 & 1.07 to 1.36 \\
\hline
\end{tabular}

CI 6.86 to 10.63 . Over $50 \%$ of the sample reported anxiety and related problems. These data more closely reflect the underlying prevalence of morbidity in the community, showing that hospital discharge data underreports the true prevalence of mental disorder in general and affective and anxiety disorders in particular. This is reflected for some physical conditions, for example, tinnitus and haemorrhoids, treated largely in the community and not appearing in our data.

The sentinel conditions identified in the study relate to smoking, the consumption of alcohol and drug use. These are most likely to be related either to the psychological effects of war service or lifestyle habits acquired during service. Alcohol-related mental disorder was significantly higher in the cohort, likely to reflect a high prevalence of alcohol use in veterans in general but more so when associated with post-traumatic stress disorder (PTSD). The excessive use of alcohol and increased risk of alcohol use disorder appears associated with a comorbidity of PTSD but interestingly is independent of severity. ${ }^{13} 14$

This indicates that specific interventions might be designed to both identify at-risk individuals but also provide effective management for both alcohol use disorders and other psychological comorbidities. ${ }^{15} 16$

Furthermore, prevention strategies are also being investigated including changing the culture and attitudes towards alcohol use in current military personnel. ${ }^{17}$ 
In contrast to the reduced mortality in Vietnam veterans, an 'all causes' standardised mortality ratio of 0.85 , $95 \%$ CI 0.77 to $0.94,{ }^{2}$ hospitalisations show a significant increase. In particular, the trends in COPD and CRF with age are a cause for concern in this population. COPD is not usually diagnosed until it is "clinically apparent and moderately advanced' and the associated costs are known to be high. ${ }^{18}$ There were no measures of disease severity in the data; however, the Global Initiative for Chronic Lung Obstructive Lung Disease (GOLD) has emphasised the importance of symptoms and GOLD severity categorisation in predicting respiratory care utilisation and decline in lung function. ${ }^{19}$ Appropriate treatment of exacerbations is a key component in COPD prevention, ${ }^{20}$ offering opportunities to improve the quality of life of those affected.

Similar considerations apply to CRF, which is an increasingly prevalent worldwide health problem, with a complex relationship with cardiovascular disease, hypertension and diabetes. ${ }^{19}$ Early detection and treatment may prevent end-stage kidney disease, ${ }^{21}$ and the associated costs of treatment.

We suggest that veterans of war and conflict are a particular at-risk group that could benefit from routine surveillance. Identification of disease and its management could be greatly facilitated by introducing a veteran 'flag' in national databases with linkage to primary care patient management systems. Sentinel disorders could then be identified and appropriate interventions designed.

To benefit serving personnel, the veterans of the future, standards should be developed for recording, in military health databases, lifestyle factors and missionspecific environmental determinants of health. This would help to ensure that epidemiological surveillance in the military meets translational requirements.

Acknowledgements Captain Conrad Flinkenberg compiled the original cohort from pay records: the study would not have been possible without his foresight. The authors are grateful for the encouragement and support of the Royal New Zealand Ex-Vietnam Services Association and the Royal New Zealand Returned and Services Association. They acknowledge the staff of New Zealand Veterans Affairs, particularly Corina Herewini, for their invaluable help in updating and formatting the service records. They also acknowledge the assistance of the analytical services staff at Ministry of Health.

Contributors BC performed the searches, designed the analysis and produced the initial report. DM conceived the idea, developed the study proposal, assisted in interpreting the results, wrote the drafts and finalised the manuscript. DT contributed to the study design and literature search, also to editing the manuscript. JB advised on the cultural aspects of the proposal, assisted in study design, advised on the interpretation of the results and commented on the manuscript.

Funding The study was funded by the New Zealand War Pensions Medical Research Trust Fund. Open access publication was funded by the Royal New Zealand Returned and Services Association.

Competing interests None declared.

Ethics approval Ethical approval was given by the New Zealand Multi-regional Ethics Committee: reference number MEC/09/08/EXP. The Ngāi Tahu
Research Consultation Committee also gave us a perspective on the Māori health aspects of our proposal.

Provenance and peer review Not commissioned; externally peer reviewed.

Data sharing statement No additional data are available.

Open Access This is an Open Access article distributed in accordance with the Creative Commons Attribution Non Commercial (CC BY-NC 4.0) license, which permits others to distribute, remix, adapt, build upon this work noncommercially, and license their derivative works on different terms, provided the original work is properly cited and the use is non-commercial. See: http:// creativecommons.org/licenses/by-nc/4.0/

\section{REFERENCES}

1. Committee to Review the Health Effects in Vietnam Veterans of Exposure to Herbicides. Veterans and agent orange: update 2010. Washington DC, 2012.

2. McBride D, Cox B, Broughton J, et al. The mortality and cance experience of New Zealand Vietnam war veterans: a cohort study. BMJ Open 2013;3:e003379.

3. The Repatriation Medical Authority. Statements of Principles. 2015. http://www.rma.gov.au/SOP/main.htm (accessed 1 Apr 2015).

4. Minshall D. Gulf War Syndrome: a review of current knowledge and understanding. J R Nav Med Serv 2014;100:252-8, Committee on the Development of a Consensus Case Definition for Chronic Multisymptom IIIness in 1990-1991 Gulf War Veterans; Board on the Health of Select Populations; Institute of Medicine. Chronic Multisymptom Illness in Gulf War Veterans: Case Definitions Reexamined. Washington (DC): National Academies Press, 2014.

5. Glover $\mathrm{G}$. Use of routinely collected data on psychiatric in-patient care. Adv Psychiatr Treat 2003;9:300-7.

6. McCormick N, Lacaille D, Bhole V, et al. Validity of myocardial infarction diagnoses in administrative databases: a systematic review. PLOS ONE 2014;9:e92286.

7. Rahman MM, Kopec JA, Anis $\mathrm{AH}$, et al. Risk of cardiovascular disease in patients with osteoarthritis: a prospective longitudinal study. Arthritis Care Res (Hoboken) 2013;65:1951-8.

8. Monson RR. Observations on the healthy worker effect. J Occup Environ Med 1986;28:425-33.

9. Waller M, McGuire AC. Changes over time in the "healthy soldier effect". Popul Health Metr 2011;9:1-9.

10. Wilson EJ, Horsley KW, van der Hoek R. The third Australian Vietnam Veterans Mortality Study 2005. Canberra: Department of Veteran's Affairs, 2005.

11. Wilson EJ, Horsley KW, van der Hoek R. Cancer incidence in Australian Vietnam Veterans Study 2005. Canberra: Department of Veteran's Affairs, 2005.

12. O'Toole BI, Catts SV, Outram S, et al. The physical and mental health of Australian Vietnam veterans 3 decades after the war and its relation to military service, combat, and post-traumatic stress disorder. Am J Epidemiol 2009;170:318-30.

13. Fuehrlein B, Ralevski E, O'Brien E, et al. Characteristics and drinking patterns of veterans with alcohol dependence with and without post-traumatic stress disorder. Addict Behav 2014;39:374-8.

14. Kline A, Weiner MD, Ciccone DS, et al. Increased risk of alcohol dependency in a cohort of National Guard troops with PTSD: a longitudinal study. J Psychiatr Res 2014;50:18-25.

15. Back SE, Killeen TK, Teer AP, et al. Substance use disorders and PTSD: an exploratory study of treatment preferences among military veterans. Addict Behav 2014;39:369-73.

16. McDevitt-Murphy ME, Murphy JG, Williams JL, et al. Brief intervention to reduce hazardous drinking and enhance coping among OEF/OIF/OND Veterans. Prof Psychol Res Pr 2015;46:83-9.

17. Waller M, McGuire AC, Dobson AJ. Alcohol use in the military: associations with health and wellbeing. Subst Abuse Treat Prev Policy 2015;10:27.

18. Celli BR, Macnee W, Members C. Standards for the diagnosis and treatment of patients with COPD: a summary of the ATS/ERS position paper (vol 23, pg 932, 2004). Eur Respir J 2006;27:242-2.

19. Bridevaux PO, Gerbase MW, Probst-Hensch NM, et al. Long-term decline in lung function, utilisation of care and quality of life in modified GOLD stage 1 COPD. Thorax 2008;63:768-74.

20. Schieppati A, Remuzzi G. Chronic renal diseases as a public health problem: epidemiology, social, and economic implications. Kidney Int Supp/ 2005:S7-S10.

21. Eknoyan G, Lameire N, Barsoum R, et al. The burden of kidney disease: improving global outcomes. Kidney Int 2004;66:1310-14. 